\title{
ERRATA
}

B. Gaymard · S. Rivaud · C. Pierrot-Deseilligny

\section{Impairment of extraretinal eye position signals after central thalamic lesions in humans}

Exp Brain Res (1994) 102:1-9

This original article was mistakenly printed under the heading of "Review".

A. Pereira Jr · E. Volchan · R.F. Bernardes

C.E. Rocha-Miranda

\section{Binocularity in the nucleus of the optic tract of the opossum}

Exp Brain Res (1994) 102:327-338

During the recording sessions the animals were anesthetized with alpha-chloralose (Sigma), injected at a rate of $10 \mathrm{mg} / \mathrm{kg}$ per hour (i.v.). The authors apologize for any inconvenience the omission of this information might have caused. 